\title{
Using Coarse Grain Geological Study to Predict the Origin of Sediments SW-Iraq
}

\author{
Abdulkadhim J. Alabidi1 ${ }^{1}$, Tahsean F. Alkanaby', Nadhir Al-Ansari² \\ ${ }^{1}$ Department of Geology, Faculty of Science, University of Kufa, Najaf, Iraq \\ ${ }^{2}$ Lulea University of Technology, Lulea, Sweden \\ Email: Abdulkhadhimj.alabidy@uokufa.edu.iq, suggestio345@gmail.com,nadhir.alansari@ltu.se
}

How to cite this paper: Alabidi, A.J., Alkanaby, T.F. and Al-Ansari, N. (2020) Using Coarse Grain Geological Study to Predict the Origin of Sediments SW-Iraq. Engineering, 12, 234-241. https://doi.org/10.4236/eng.2020.124019

Received: March 5, 2020

Accepted: April 10, 2020

Published: April 13, 2020

Copyright (c) 2020 by author(s) and Scientific Research Publishing Inc. This work is licensed under the Creative Commons Attribution International License (CC BY 4.0).

http://creativecommons.org/licenses/by/4.0/

\begin{abstract}
This research deals with coarse grain sediments obtained from sieving of quaternary depression and valley fill sediments from desert and desert boarder's regions southwest Najaf city-Iraq. Physical, chemical and mineralogical analyses of these sediments were done to reveal the sedimentary origin of these sediments. The results indicated that parent rocks of these sediments were not from the Arabian shield where they were transported for short distances from sedimentary rocks cover that is located at the outskirts of the Arabian shield.
\end{abstract}

\section{Keywords}

Arabian Shield, Valley Fill Sediments, Desert Gravel, Desert Border,

Najaf-Iraq

\section{Introduction}

The study area (Figure 1) falls in Bahr Al-Najaf and surrounding areas west and southwest of Najaf city-Iraq, within the transition site between inner and outer of Arabian platforms according to Tectonic map of Iraq [1]. There are different geological formations exposed within the area. All these formations are composed of sedimentary rocks.

Coarse grained sediments (locally called desert gravel) can be obtained from sieving of depression, and valley fills sediments (different in composition, size and thickness of the sediments) and then washed off (Figure 2). These sediments were found within the desert and desert-borders regions in the west and south west of Najaf city-Iraq.

Desert gravel is a part of coarse-grained sediments. This kind of gravel is usually used as a coarse aggregate in concrete industry in construction works [2]. The distance between the two areas in Figure 2 is about 5 kilometers. 


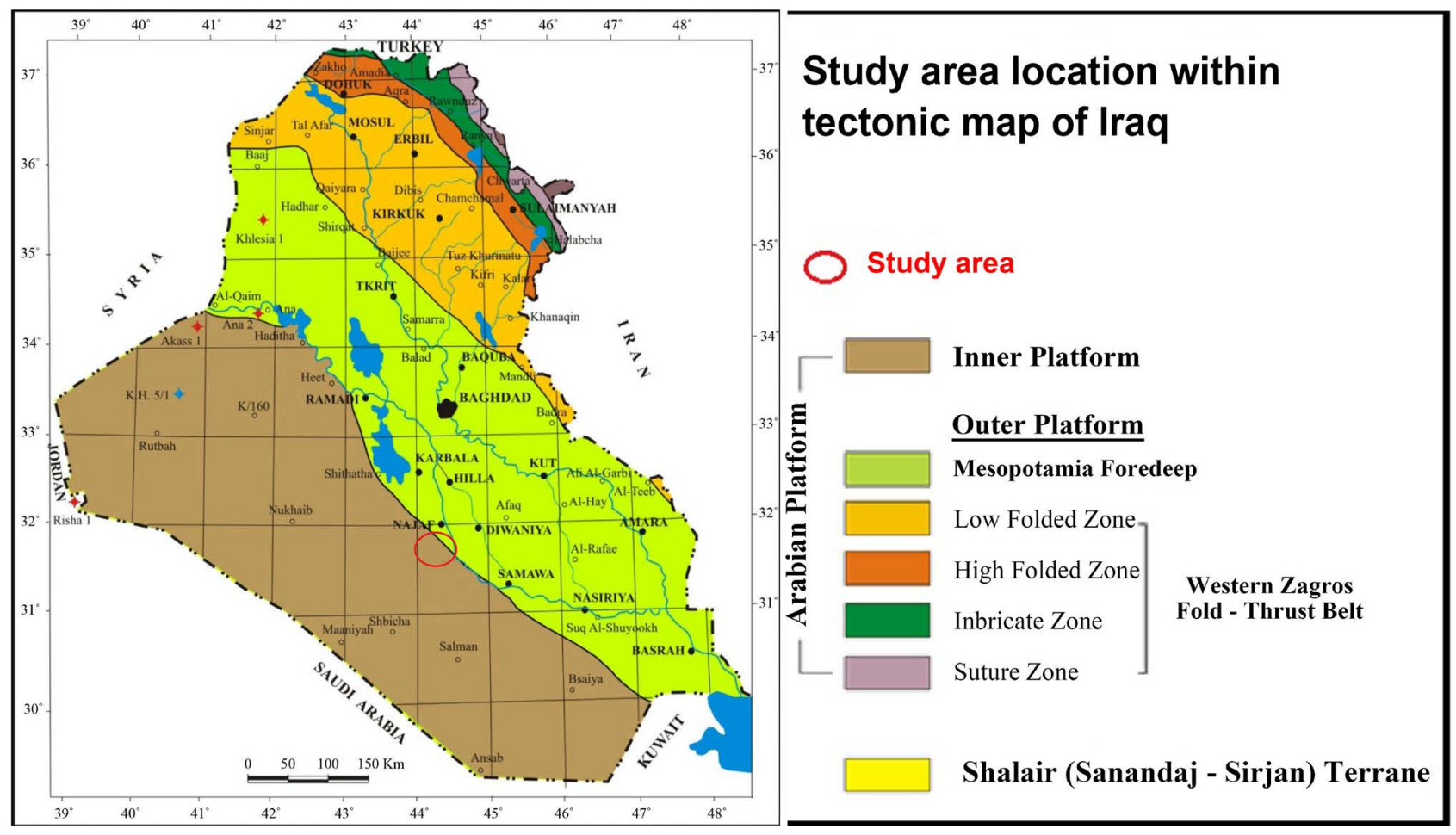

Figure 1. Study area location within the tectonic map of Iraq after [1].

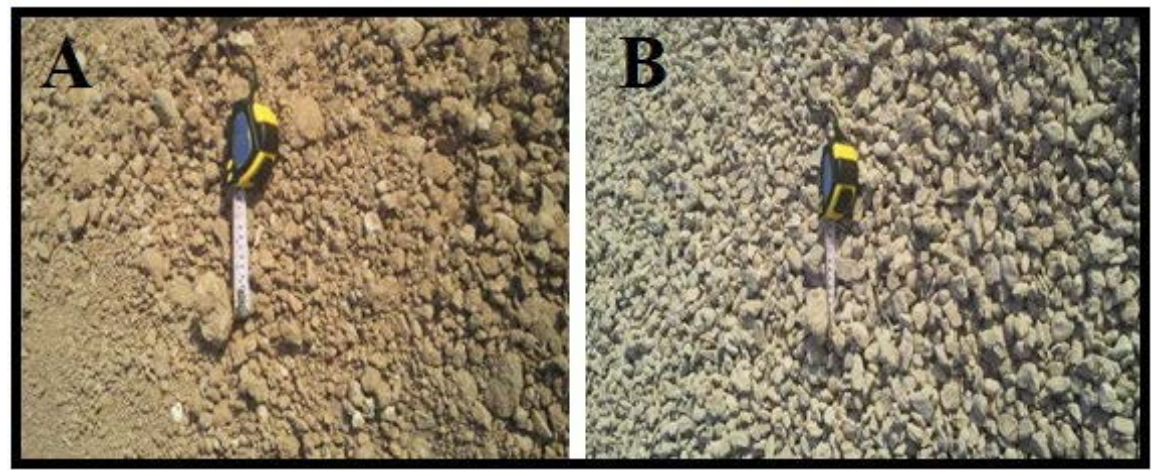

Figure 2. (A) Valley fill sediments; (B) Coarse grained sediments (desert gravel).

This paper aims to predict the origin of these sediments and the source area by studying the coarse grain sediments and their mineralogy.

\section{Sediment Geological Description}

In the study area, coarse valley fill sediments are deposits resulting from seasonal action of the valleys were studied. They are distributed from the north of Arabia Peninsula towards the northeast (towards the Mesopotamian basin) due to the gentle slope from 300 - $400 \mathrm{~m}$ (a.s.l.) along Iraqi-Saudi Arabian border [3] and more towards the southwest to $(20$ - 150) m (a.s.l.) along western side of Euphrates river. Some of these sediments are transported into Bahr $\mathrm{Al}$ Najaf and surrounding areas. The age of these deposits is Pleisto-Holocene according to Al-Zubaidi (1988) [4] or Holocene according to [5] [6]. These deposits are 
usually exposed at the surface and can be described as friable unsorted deposits (vary in size from clay to boulders) (Figure 2).

\section{Methodology}

Reconnaissance field visits to the area of quarrying and sieving factories of these sediments were conducted. Big sample of coarse grain sediments up to $40 \mathrm{~kg}$ in weight were collected, and mixed very well. Then, samples were divided several times. Finally, representative unbiased samples composed of 21 pebbles of different sizes from gravel to boulder were separated. These pebbles were studied physically, chemically, mineralogically using X-ray and stereoscope. Twenty one slides were made from these pebbles from different samples.

\subsection{Physical Analysis}

Hand specimen study of coarse grain sediments illustrated that they can be described as white in color, differ in sizes, hard, irregular shapes, and poorly polished. They contained pockets on the surface. For this reason, these gravel samples required to be washed for several times to clean them from undesired dust and clay before using them in concrete aggregates (Figure 3(A)). These sediments were sub angular to sub rounded in shape. Many pebbles showed traces of joints and fractures or veins, which indicated that the parent (source) rocks were previously affected (Figure 3(B)). These rocks are carbonates.

Roundness study of the sediments according to [7] revealed that these sediments were sub rounded according to powers (1953) in [8] and sub angular to sub rounded by using roundness and sphericity methods according to [9]. This result means that the distance of transporting these sediments was short. This is because those sedimentary rocks tend to be more rounded even though the distance of transportation is short [10], and the carbonate rocks ability to be more rounded than harder rocks [11] (Table 1).

\subsection{Chemical and X-Ray Analysis}

Primary test revealed that most of the pebbles samples showed chemical reaction

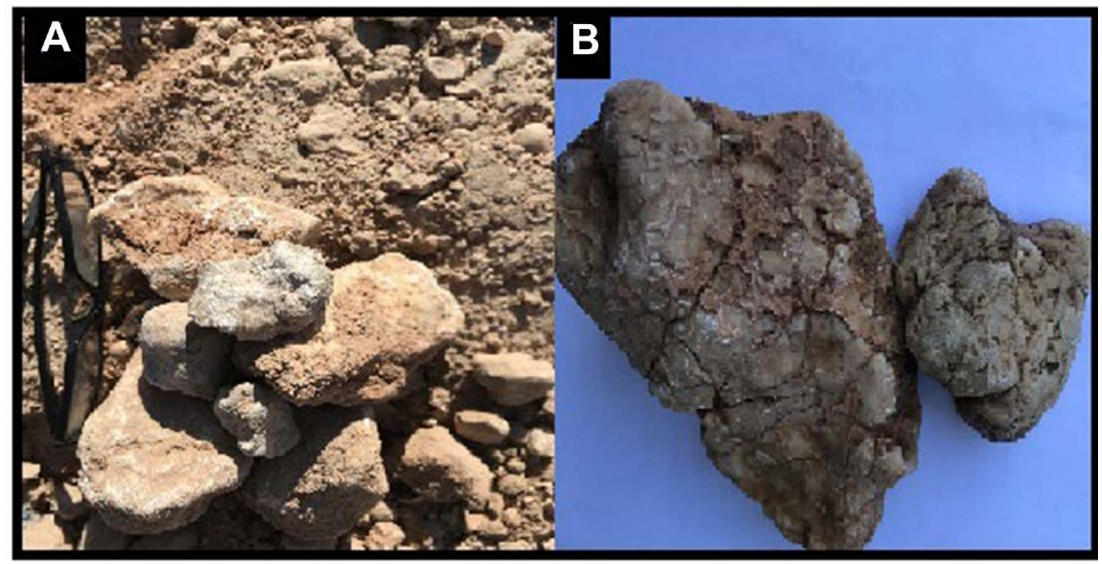

Figure 3. Coarse grains sediments having joints, fractures, and pockets filled with clay. 
Table 1. Roundness and sphericity for the studied pebbles.

\begin{tabular}{|c|c|c|}
\hline No & Roundness & Sphericity \\
\hline 1 & 0.24 & 0.32 \\
\hline 2 & 0.35 & 0.26 \\
\hline 3 & 0.27 & 0.33 \\
\hline 4 & 0.33 & 0.28 \\
\hline 5 & 0.33 & 0.26 \\
\hline 6 & 0.35 & 0.30 \\
\hline 7 & 0.25 & 0.41 \\
\hline 8 & 0.30 & 0.27 \\
\hline 9 & 0.45 & 0.30 \\
\hline 10 & 0.41 & 0.31 \\
\hline 11 & 0.35 & 0.24 \\
\hline 12 & 0.35 & 0.30 \\
\hline 13 & 0.35 & 0.31 \\
\hline 14 & 0.33 & 0.28 \\
\hline 15 & 0.33 & 0.30 \\
\hline 16 & 0.37 & 0.29 \\
\hline 17 & 0.36 & 0.33 \\
\hline 18 & 0.03 & 3.39 \\
\hline 19 & 0.34 & 0.40 \\
\hline 20 & 0.44 & 0.42 \\
\hline 21 & 0.33 & 0.27 \\
\hline Average & 0.34 & 0.45 \\
\hline
\end{tabular}

with $\mathrm{HCl}$ acid. This result gives an indication that most of these pebbles are composed of carbonate or at least contains calcite. The chemical analysis of the studied coarse grains sample showed the following results tabulated in Table 2.

It should be mentioned, however, that there are no significant differences in chemical composition among the pebbles of different sizes.

$\mathrm{X}$-ray test for the studied sample showed that the pebbles were mainly composed of calcite as the dominant mineral and few silica and other minerals. The result of X-ray tests were compatible with those results obtained from the chemical analysis.

\subsection{Optical analysis and Mineralogy}

Optical study of twenty-one slides (made from 21 pebbles of the representative sample) using polarized microscope showed that all slides were mainly composed of calcite mineral; vary in size from micrite to sparry calcite (sparite) (Figure 4(A) and Figure 4(B)). Dolomite was found in eight slides of the studied samples (Figure $4(C)$ ). Clay minerals were noticed in two slides of the total slides (Figure 4(D)), and iron oxide in one slide (Figure 4(E)). 
Table 2. The average results of the chemical analysis for the coarse grain sediment's samples.

\begin{tabular}{cccccc}
\hline Compound & $\mathrm{SiO}_{2}$ & $\mathrm{Fe}_{2} \mathrm{O}_{3}$ & $\mathrm{CaO}$ & $\mathrm{MgO}$ & L.O.I \\
\hline Percentage & 0.68 & 2.3 & 54.07 & 1.11 & 41.9 \\
\hline
\end{tabular}

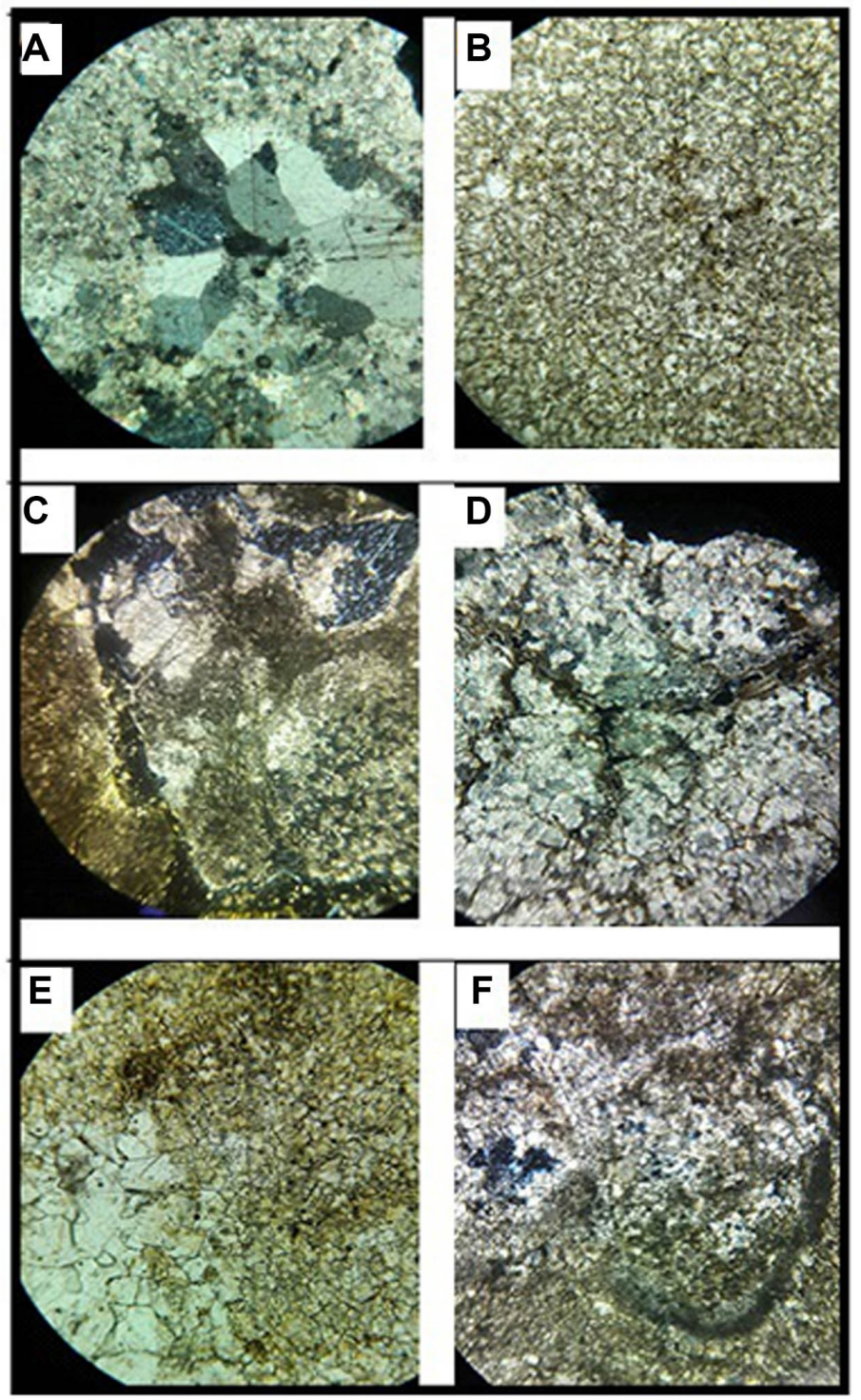

Figure 4. (4X): (A) Spary calcite-XPL, (B) Micrite-PPL, (C) Dolomite-XPL, (D) Clay minerals-XPL, (E) Iron oxides-PPL, (F) Diagenesis-XPL.

Eleven slides (more than 50\%) showed different kinds of cementation (Figure 5(A)), and six slides showed blocky cement (Figure 5(B)).

Fossils were found in $28 \%$ of the studied slides like, Gastropoda, Nummelites sp. etc. (Figure 5(C) and Figure 5(D)), and many non clear fossils were found. Organic matter was also found in about $30 \%$ of the slides. These can be called Biomicrite according to [8]. Some slides completely composed of fossils (Figure $5(C))$. 


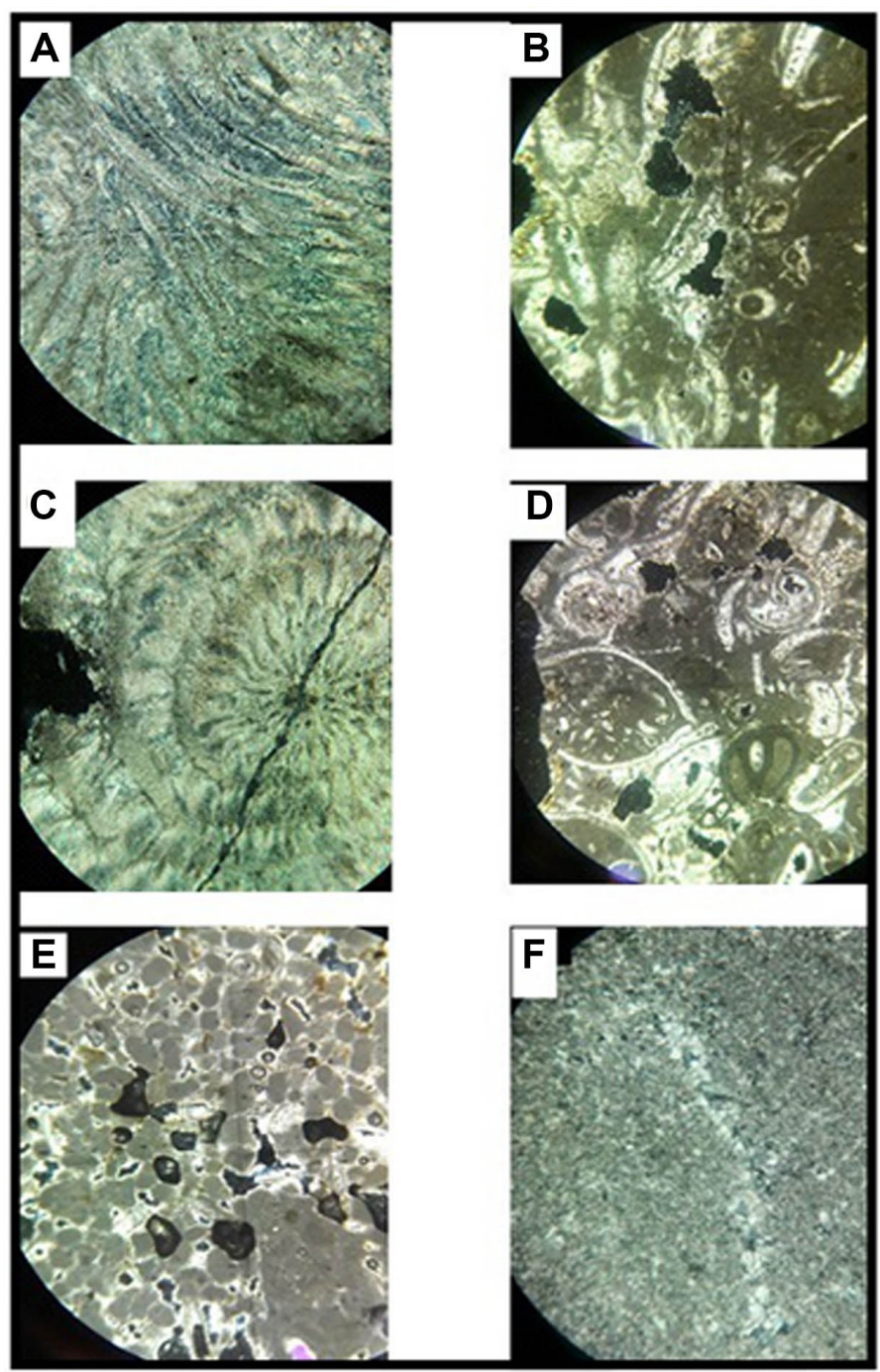

Figure 5. (4X): (A) cement materials filled Fossils, (B) Blocky cement, (C \& D) Different kinds of fossils, (E) pellets, (F) stylolite.

Micro veins were noticed in more than one slide (Figure 5(C)) and other slides showed pellets (Figure 5(E)), stylolite (an indication of compaction in parent rocks) was seen in one slide (Figure $5(\mathrm{~F})$ ).

\section{Discussion}

The topography of the area and valley's direction indicates that the southwestern part of Iraq and northern part of Arabia Sudia was the source area of these sediments. Unsorting of these sediments indicates the sudden deposition of these sediments. This is due to the sudden change in the velocity of the seasonally rivers or sheet runoff due to entering depressions or flat areas.

The mineralogical study of coarse grains indicates that the origin of these sediments is sedimentary rocks and not igneous or metamorphic rocks. This is evident from the content of carbonates within the samples.

The irregularity, angularity, and poorly polished surfaces of the studied peb- 
bles revealed that the source rocks (parent rocks) of these sediments are not so far. These pebbles found sub angular to sub rounded despite the fact that they are sedimentary carbonate rocks, which tend to be more rounded with short distances of transportation.

According to above, the parent rocks of these sediments are not the Arabian shield, but the sedimentary cover located at the outskirts of the Arabian shield.

The results of chemical analysis and X-ray test coincide with the mineralogical study in this paper are compatible with the chemical analysis of calcareous sedimentary rocks within Iraq according to [12]. These results verify the foregone conclusions about the origin of the studied sediments.

\section{Conclusions}

The area of study falls in Bahr Al-Najaf and surrounding areas west and southwest of Najaf city-Iraq. Within this area, there are plenty of coarse-grained sediments exposed on the surface. These sediments are usually used in concrete mixture. The origin of these sediments is not well known. Different techniques were used to reveal the origin of these sediments (parent rocks) within the studied area.

Physical, chemical, and mineralogical study of coarse grain sediments, obtained from sieving of quaternary depression and valley fills sediments, revealed that these sediments were transported for short distances. The source area of studied sediments was not the Arabian shield but the sedimentary cover on the outskirts of the Arabian shield.

\section{Acknowledgements}

The authors would like to thank Kufa University and Lulea University of Technology for their support in using the facilities required for this research.

\section{Conflicts of Interest}

The authors declare no conflicts of interest regarding the publication of this paper.

\section{References}

[1] Fouad, S.F. (2012) Tectonic Map of Iraq, Scale 1:1000000. 3rd Edition, GEOSURV, Baghdad.

[2] Migbil, A.A., Alabidi, A.J. and Musa, R. (2012) Suitability of Desert Gravel for Concrete. Alkufa Engineering Bull, 4, 1-15. (In Arabic)

[3] Ma'ala, K.A. (2009) Geomorphology of Iraqi Southern Desert. Iraqi Bulletin of Geology and Mining, Special Issue: Geology of Iraqi Southern Desert, 5, 7-23.

[4] Al Zubaidy, J.H. (1988) Engineering Geological Study of Selected Areas in Bahr Al-Najaf (Middle Iraq). Unpublished Thesis, University of Baghdad, 129 p. (In Arabic).

[5] Yacoub, S.Y. (2011) Stratigraphy of the Mesopotamian Plain. Iraqi Bulletin of Geology and Mining Special Issue, No. 4, 47-82. 
[6] Jassim, R.Z. and Al-Jibury, B.S. (2009) Stratigraphy of the Iraqi Southern Desert. Iraqi Bulletin of Geology and Mining, Special Issue: Geology of the Iraqi Southern Desert, 5, 53-67.

[7] Lal, R. and Shukla, M.K. (2008) Principles of Soil Physics. Mrcel Dekker Inc., New Yourkm, $624 \mathrm{p}$.

[8] Folk, L.R. (1980) Petrology of Sedimentary Rocks. Hemphill Publishing Company, Texas, $190 \mathrm{p}$.

[9] Power, M.C. (1982) Comparison Chart for Estimating Roundness and Spherisity. AGI Dana Sheet 18, American Geological Institute.

[10] Lindsey, D.A., Langer, W.A. and Van Gosen, B.S. (2007) Using Pebble Lithology and Roundness to Interpret Gravel Provenance in Piedmont Fluvial System. https://doi.org/10.1016/j.sedgeo.2007.02.006

[11] Jassim, H.K. (2009) Petrology and Sedimentology of Al-Makdadiya Formation in Badra Area Eastern Iraq. Unpublished Thesis, University of Baghdad, 155 p.

[12] Alkaragoly, N.A. (1979) Geochemistry of Industrial Rocks and Minerals. Times Co. Press, Bagdad, 166 p. (In Arabic). 